\title{
Effect of Bacillus flexus on the Degradation of Epoxy Resin Varnish Coating in Seawater
}

\author{
Sanxi Deng ${ }^{1, \#, ~ J i n y i ~ W u ~}{ }^{1, \#}$, Yadong $\mathrm{Li}^{1}$, Gang Wang ${ }^{1}$, Ke Chai ${ }^{1, *}$, Aimin $\mathrm{Yu}^{2}$, Fuchun Liu ${ }^{3}$ \\ ${ }^{1}$ Key Laboratory of Advanced Materials of Tropical Island Resources (Hainan University), Ministry of \\ Education, Material and Chemical Engineering College, Hainan University, Haikou 570228, China \\ ${ }^{2}$ Department of Chemistry and Biotechnology, Swinburne University of Technology, Australia 3166 \\ ${ }^{3}$ Key Laboratory of Nuclear Materials and Safety Assessment, Institute of Metal Research, Chinese \\ Academy of Sciences, Shenyang 110016, China \\ *E-mail: chaike888@sina.com \\ \#First authors: these authors contributed equally to this work.
}

doi: $10.20964 / 2019.01 .64$

Received: 19 August 2018 / Accepted: 8 November 2018 / Published: 30 November 2018

\begin{abstract}
Protective coatings have been being widely applied on the surface of metallic materials to protect against corrosion. However, there is still little known about the degradation of coatings caused by microbiological attack in seawater. As one of the most widespread species, Bacillus species are of great importance in the deterioration and degradation of materials. In this paper, the effect of Bacillus flexus on the degradation of an epoxy resin varnish coating in seawater was investigated. All the experiments were conducted in either sterile seawater or seawater containing Bacillus flexus. The electrochemical characteristics of the coatings in both kinds of seawater were monitored with electrochemical impedance spectroscopy (EIS). The reduction of the corrosion resistance of the coating exposed to seawater containing Bacillus flexus between 1 day of immersion and 19 days of immersion was evidently larger when compared with that in sterile seawater, which indicated that Bacillus flexus could remarkably decrease the corrosion resistance of the coating and potentially result in degradation of the coating. In addition, scanning electron microscopy (SEM) was employed for characterizing the surface morphology of the coatings before and after immersion. After 30 days of immersion, chalking traces and some tiny holes emerged on the surface of the coatings exposed to seawater containing Bacillus flexus, which was mainly ascribed to the biofilm formed by Bacillus flexus and their metabolic activities. The results demonstrated that the epoxy resin varnish coating was degraded by Bacillus flexus, which was further confirmed by the results obtained from Fourier transform infrared spectroscopy (FTIR).
\end{abstract}

Keywords: Epoxy resin varnish coating; Bacillus flexus; Degradation; Electrochemical impedance spectroscopy; Corrosion 


\section{FULL TEXT}

(C) 2019 The Authors. Published by ESG (www.electrochemsci.org). This article is an open access article distributed under the terms and conditions of the Creative Commons Attribution license (http://creativecommons.org/licenses/by/4.0/). 